\title{
Calculating Simulation of the Impact of Additional Forces on the Vessel When Altering the Course
}

\author{
Pham Ky Quang1,*, Vu Van Duy², Trinh Xuan Tung ${ }^{1}$, Nguyen Thi Lien³, Nguyen Thanh Nhat Lai ${ }^{4}$ \\ ${ }^{1}$ School of Excellent Education, Vietnam Maritime University, Vietnam. \\ ${ }^{2}$ School of Mechanical Engineering, Vietnam Maritime University, Vietnam. \\ ${ }^{3}$ Faculty of Economics, Vietnam Maritime University, Vietnam. \\ ${ }^{4}$ Maritime Insitute, Ho Chi Minh City University of Transport, Vietnam. \\ *Corresponding author: Pham Ky Quang \\ *ORCID: 0000-0002-7534-7207
}

\begin{abstract}
When the vessel alters her course, corresponding to different velocity, the additional force will be applied differently. If the magnitude of the additional force increases beyond the allowed limit, the altering of ship's course will be more difficult, more dangerous and the ship may fall into an unstable equilibrium, which is one of the main causes the ship to capsize. Stemming from this problem, the article researched: The additional force $(P)$ acting on the vessel which is the hydrodynamic force of the fluid acting on the ship's hull during altering her course, analyzed into three components: additional centrifugal force $\left(F_{l t}\right)$, additional resistance force $\left(R_{m}\right)$ and additional torque $\left(M_{g l}\right)$. The article applied CFD (Computational Fluid Dynamics) with Fluent Ansys to calculate the simulation of the impact of additional force on the vessel when altering the direction of motion. The result of simulation calculation is based on the same data according to the Froude standard of M/V TAN CANG FOUNDATION with a tonnage of 420 TEUs. The results of the empirical were verified at the Ship Model Test Tank of Vietnam Maritime University.
\end{abstract}

Keywords: additional force, alter the course, Computational Fluid Dynamics (CFD), ship, simulation.

\section{BUILDING THE MODELS FOR RESEARCH}

The balance of the ship in the water environment is due to the impact of the Archimedes thrust. When the ship moves at a certain speed, the propellant generated by the propeller will be balanced with the resistance of the fluid around the ship's hull. When the ship changes its course, especially when maneuvering the ship, the current around the ship's hull deviates from the longitudinal axis of the ship, leading to a difference in pressure between the two sides of the ship. At which time, the fluid impact on the ship's hull an "additional force".

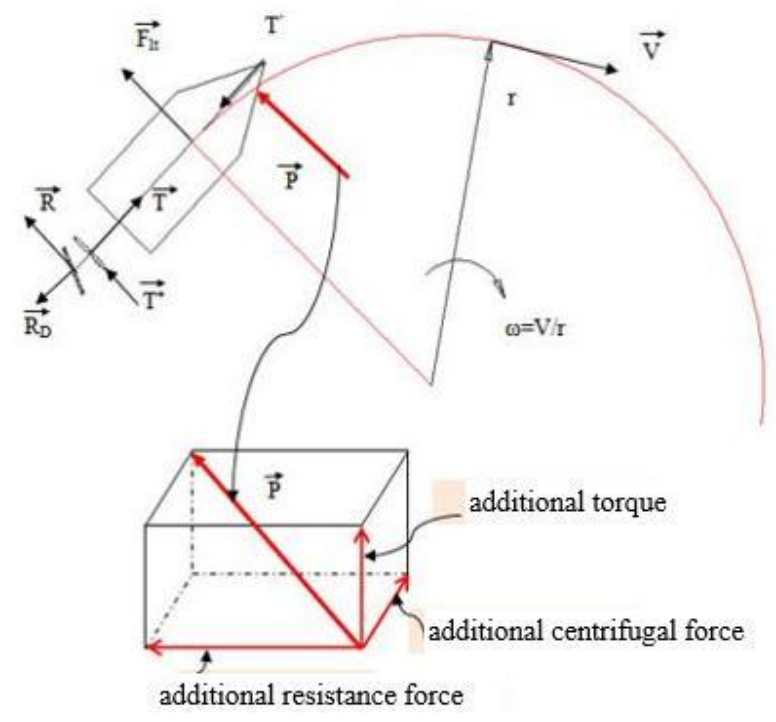

Figure 1: Building the research's model with additional force components acting on the vessel

Where:

$r$ : the radius of rotation $(\mathrm{m})$;

$V_{s}:$ the ship velocity $(\mathrm{m} / \mathrm{s})$;

$\omega$ : the corresponding angular velocity $(\mathrm{rad} / \mathrm{s})$;

$P$ : the additional force $(\mathrm{N})$;

$F_{l t}$ : the additional centrifugal force $(\mathrm{N})$;

$T$ : the thrust produced by the propeller $(\mathrm{N})$;

$T^{*}$ : the horizontal force created by ship propeller $(\mathrm{N})$;

$T^{\prime}$ : the resistance force acting on ship's hull (N);

$R$ : the steering force acting on the rudder $(\mathrm{N})$;

$R_{D}$ : the resistance force acting on the rudder $(\mathrm{N})$. 
Analyzing the additional force $\mathrm{P}$ that consisting of three basic components:

\section{- Additional centrifugal force $\left(F_{l t}\right)$ : When $P$ is projected perpendicular to the longitudinal axis of the ship and it has the same direction as the additional centrifugal force due to the mass of the object rotating around the pivot point, so-called as an additional component of centrifugal force.}

- Additional resistance force $\left(R_{m}\right)$ : When projecting $P$ force on the longitudinal direction and they have the opposite direction of movement of the ship, it is called the additional resistance force.

- Additional torque $\left(M_{g l}\right)$ : From the component due to $P$ projecting vertically and they deviate from the axis of the ship by a certain distance, thus creating the additional torque.

When the vessel is keeping on her course with any velocity, the resistance force $T^{\prime}$ and the thrust $T$ are equal in magnitude. Besides that, the gravity and repulsion of the Archimedes thrust are always balanced. At this time, the propeller has the horizontal force $T^{*}$ making the ship's bow tend to starboard (if the propeller is right hands). When the ship alters the course, the pressure distribution on the two sides of the rudder will be asymmetric, creating residual pressure due to the flow acting on the rudder and dividing it into two components, including the steering force $R$ and the resistance force $R_{D}$. At the same time, the additional centrifugal force $F_{l t}$ and the additional force $P$ appeared.

\section{MATHEMATICAL PRINCIPLES}

When the ship alters her course, the current impact on vessel's shell will make additional forces (not considering the effects of the wind). To determine the additional force as well as to analyse its effects on the ship's maneuverability, we gave a research model according to Fig 2 [1-8].

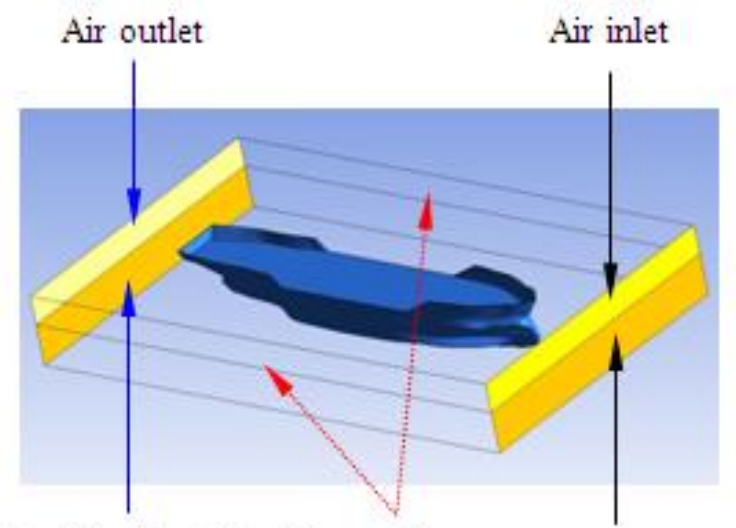

Water-liquid outlet Free surface Water-liquid inlet

Figure 2: The boundary conditions of the two-phase model (water phase and air phase)
We apply CFD in researching the effects of current on course keeping abilities of vessels navigating in the area. For three proposed problems, the VOF (volume of fluid) model, mixture for cavitation problem and others models, such as [24]: $k-\varepsilon, k-\omega, \ldots$ are used [9-11].

The method of VOF for solving differential equations with various phases, by adding the value of volume fraction, if $\alpha_{k}$ is the volume fraction of the number $k$ phase, then:

$$
\sum_{k=1}^{n} \alpha_{k}=1
$$

If $\rho_{k}$ is the density of the number $k$ phase, the density of the mixture will be:

$$
\rho=\sum_{k=1}^{n} \alpha_{k} \rho_{k}
$$

Then, we solve major differential equations to determine specific values:

$$
\frac{\partial \alpha_{k}}{\partial t}+\nabla\left(\alpha_{k} \vec{v}_{k}\right)=\frac{1}{\rho_{k}}\left[s_{\alpha_{k}}+\sum_{k=1}^{n}\left(\dot{m}_{p k}-\dot{m}_{k p}\right)\right]
$$

The value of volume fraction is determined by time step:

$\frac{\alpha_{k}^{n+1} \rho_{k}^{n+1}-\alpha_{k}^{n} \rho_{k}^{n}}{\Delta t}+\sum_{f}\left(\rho_{k}^{n+1} U_{k}^{n+1} \alpha_{k f}^{n+1}\right)=\left[s_{\alpha_{k}}+\sum_{k=1}^{n}\left(\dot{m}_{p k}-\dot{m}_{k p}\right)\right] V$

In the equation (4):

$n$ : the previous time step;

$(n+1):$ the current time step;

$\alpha_{k f}$ : the representative value of volume fraction of the number $k$ phase;

$V$ : the volume of the calculating element;

$U_{f}$ the volume of water flowing through the surface according to linear methods;

$\dot{m}_{k p}$ : the mass transferred from phase number $\mathrm{p}$ to phase number $\mathrm{k}$;

$s_{\alpha k}=0$

The velocity distribution and energy can be determined by momentum equation and energy equation:

$$
\begin{aligned}
& \frac{\partial}{\partial t}(\rho \vec{v})+\nabla(\rho \vec{v} \vec{v})=-\nabla p+\nabla\left[\mu\left(\nabla \vec{v}+\nabla \vec{v}^{t}\right)\right]+\rho \vec{g}+\vec{F} \\
& \frac{\partial}{\partial t}(\rho E)+\nabla(\vec{v}(\rho E+p))=\nabla\left(k_{e f f} \nabla T\right)+s_{h}
\end{aligned}
$$


$E$ : energy and the value of E can be determined according to equation (7):

$$
E=\frac{\sum_{k=1}^{n} \alpha_{k} \rho_{k} E_{k}}{\sum_{k=1}^{n} \alpha_{k} \rho_{k}}
$$

Applying CFD with Fluent-Ansys to calculate the simulation of the additional force when the vessel altering the direction of motion, that using the same data as Froude standard of M/V TAN CANG FOUNDATION:

The input value includes:

- Simultaneous velocity of model ship: $V_{m}=\{0.45 ; 0.55$; $0.65 ; 0.75\}(\mathrm{m} / \mathrm{s})$.

- The value of the ship's course changing: $\theta=\left\{010^{0}\right.$; $\left.020^{0} ; 030^{\circ}\right\}$ (degree).

The output value: the pressure acting on the ship's hull, the pressure distribution, the pressure coefficient, the phase distribution, velocity,...

The values of the parameter of real problems and models are converted according to Froude's uniform criteria as follows [12-15]:

$$
F_{n}=\frac{V_{s}^{2}}{L g}
$$

Where: $L$ is the ship's length (m)

$$
\frac{\left(L_{m} \cdot g_{m}\right)^{1 / 2}}{V_{m}}=\frac{\left(L_{s} \cdot g_{s}\right)^{1 / 2}}{V_{s}}
$$

Inferred: $\frac{V_{s}}{V_{m}}=\sqrt{k} \quad \frac{S_{s}}{S_{m}}=k^{2}$

$$
F_{s}=k^{3} \times F_{m}
$$

$$
\begin{aligned}
& M_{s}=k^{4} \cdot M_{m} \\
& k=\frac{L_{s}}{L_{m}}
\end{aligned}
$$

Where:

$F_{s}$ and $M_{s}$ are the force and moment according to the real problem, respectively.

$F_{m}$ and $M_{m}$ are the force and moment according to the research vessel model, respectively.

$k$ : the geometric uniformity coefficient and value $k$ is 100 , therefore, the velocity for the corresponding ship model problem is converted:

$$
V_{m}=\frac{V_{s}}{k^{\frac{1}{2}}}
$$

\section{ANALYSIS OF SIMULATION RESULTS AND EXPERIMENTAL VERFICATION}

\section{III.I. Calculation results simulated when the vessel changed her courses}

Fig 3 to Fig 9 described the results of the simulation calculation of the pressure distribution on the ship and the pressure coefficient, in the case when the ship alters the course $\theta=\left\{010^{\circ} ; 020^{\circ} ; 030^{\circ}\right\}$, with velocity values $V_{m}=0.45$ $\mathrm{m} / \mathrm{s}$ and $0.75 \mathrm{~m} / \mathrm{s}$ for $2 \mathrm{D}$ and $3 \mathrm{D}$ problems, respectively. The specific pressure distribution value is represented by the color column to the left of each figure. The pressure coefficient values in different cases are shown in detail on the corresponding graphs.

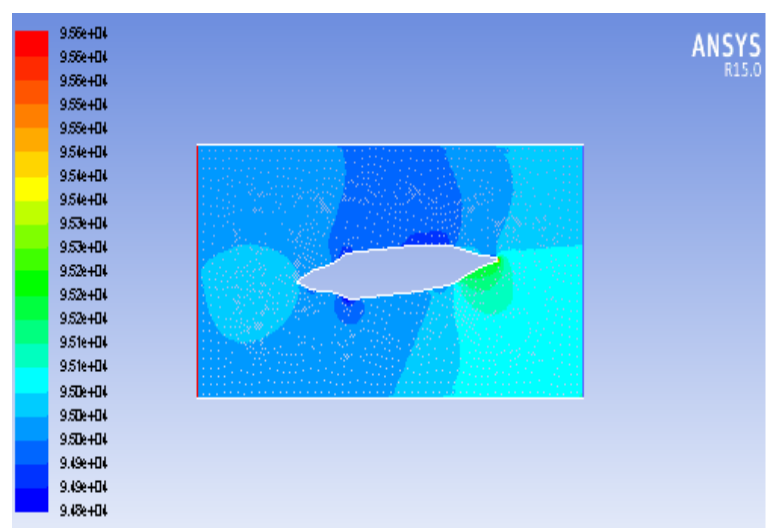

a)

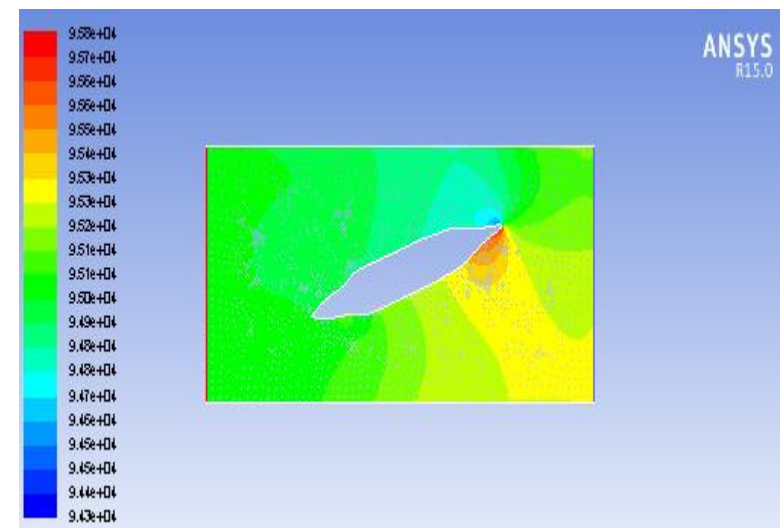

b)

Figure 3: The simulation results of vessel pressure distribution with $2 \mathrm{D}$ problem, when $V_{m}=0.45 \mathrm{~m} / \mathrm{s}$ : a) $\theta=010^{0}$; b) $\theta=020^{0}$ 
International Journal of Engineering Research and Technology. ISSN 0974-3154, Volume 13, Number 10 (2020), pp. 2778-2787

(C) International Research Publication House. https://dx.doi.org/10.37624/IJERT/13.10.2020.2778-2787

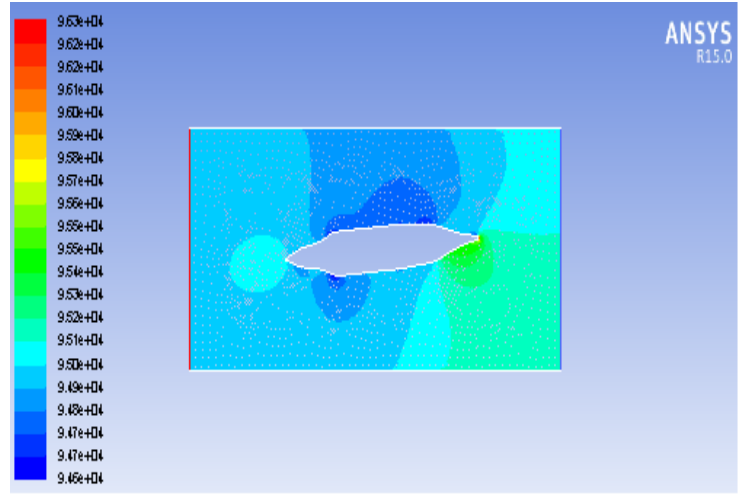

a)

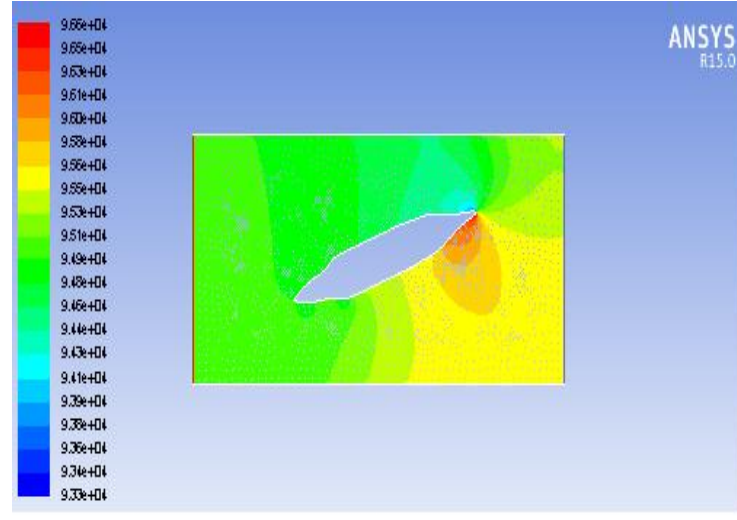

b)

Figure 4: The simulation results of vessel pressure distribution with $2 \mathrm{D}$ problem, when $\mathrm{Vm}=0.75 \mathrm{~m} / \mathrm{s}$ : a) $\theta=010^{0}$; b) $\theta=020^{0}$

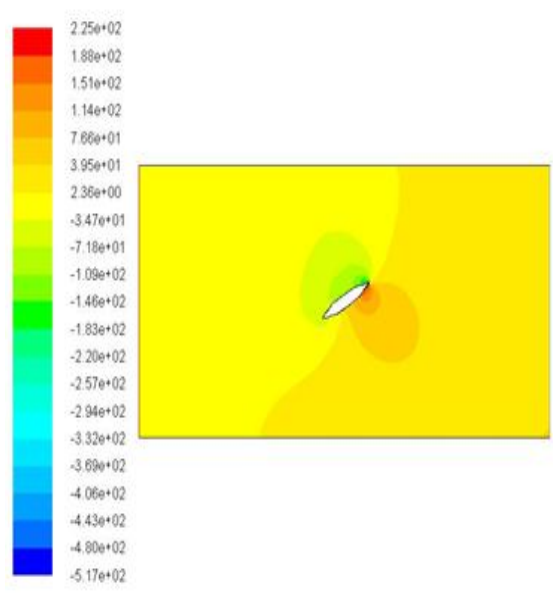

a)

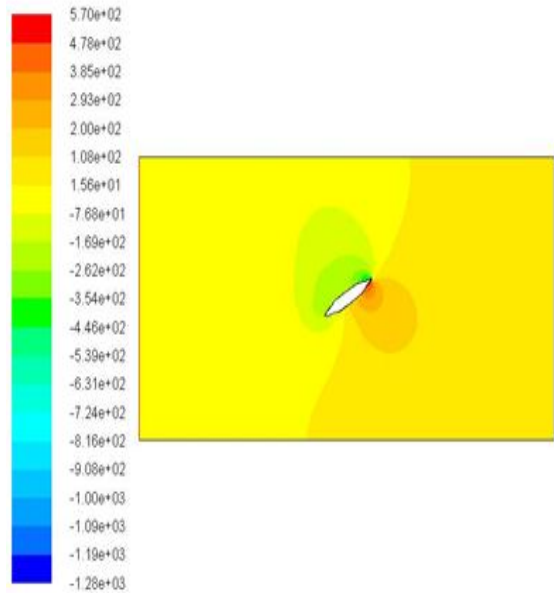

b)

Figure 5: The simulation results of vessel pressure distribution with $2 \mathrm{D}$ problem, when $\theta=030^{0}:$ a) $\left.V_{m}=0.45 \mathrm{~m} / \mathrm{s}: \mathrm{b}\right) V_{m}=0.75 \mathrm{~m} / \mathrm{s}$

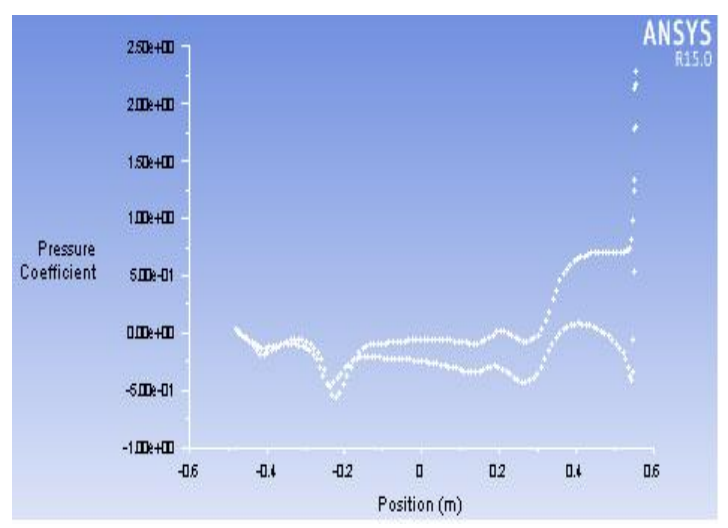

a)

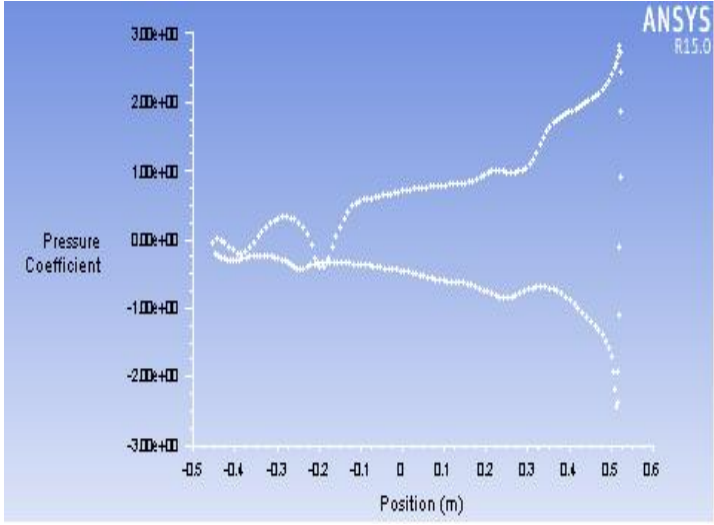

b)

Figure 6: The simulation results of the pressure coefficient with the $2 \mathrm{D}$ problem, when $V_{m}=0.45 \mathrm{~m} / \mathrm{s}$ : a) $\theta=010^{0}$; b) $\theta=020^{0}$ 
International Journal of Engineering Research and Technology. ISSN 0974-3154, Volume 13, Number 10 (2020), pp. 2778-2787

(C) International Research Publication House. https://dx.doi.org/10.37624/IJERT/13.10.2020.2778-2787

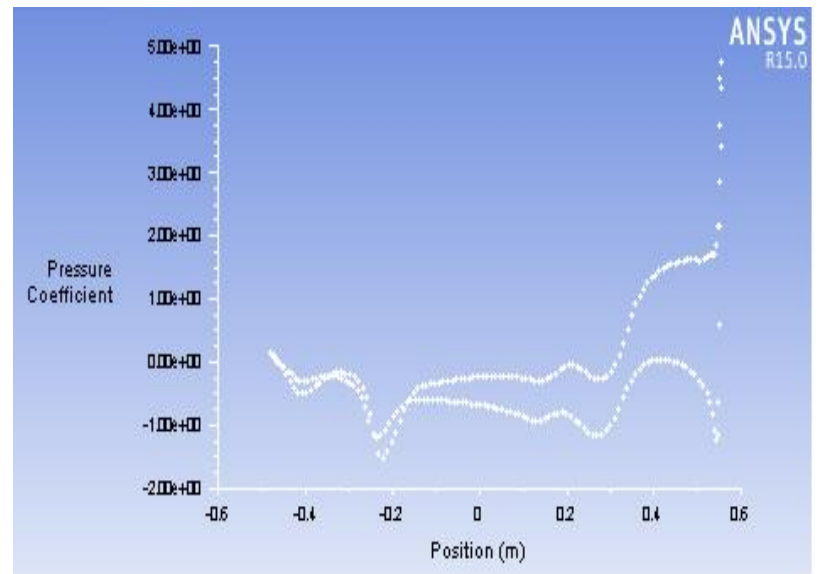

a)

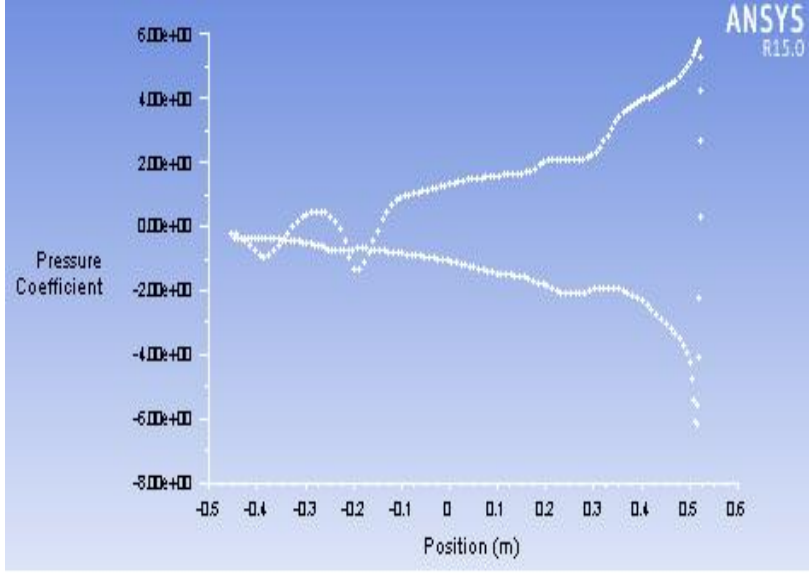

b)

Figure 7: The simulation results of the pressure coefficient with the 2D problem, when $V_{m}=0.75 \mathrm{~m} / \mathrm{s}:$ a) $\theta=010^{0}$; b) $\theta=020^{0}$

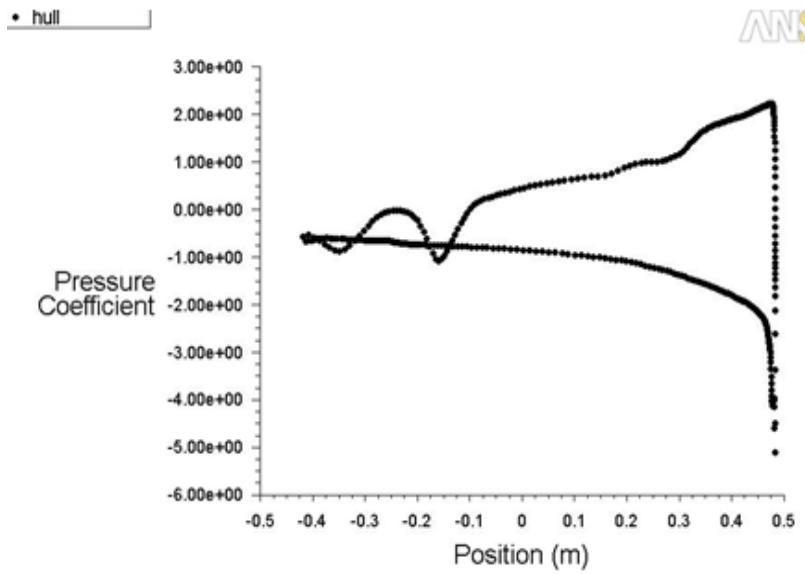

a)

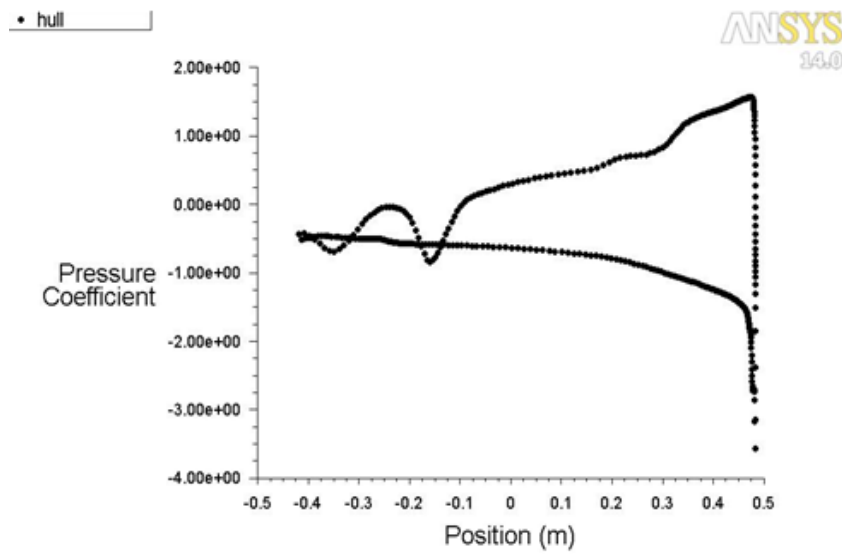

b)

Figure 8. The simulation results of the pressure coefficient with the $2 \mathrm{D}$ problem, when $\theta=030^{\circ}:$ a) $\left.V_{m}=0.45 \mathrm{~m} / \mathrm{s} ; \mathrm{b}\right) V_{m}=0.75 \mathrm{~m} / \mathrm{s}$

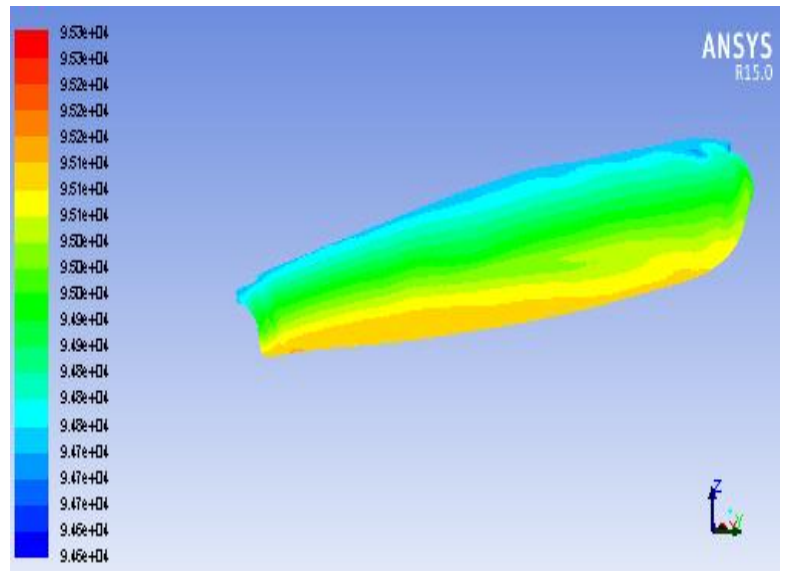

a)

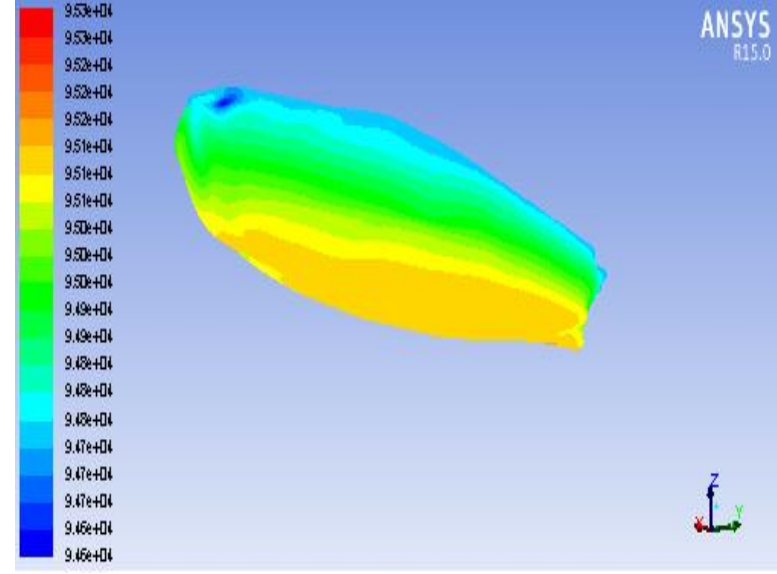

b) 
International Journal of Engineering Research and Technology. ISSN 0974-3154, Volume 13, Number 10 (2020), pp. 2778-2787

(C) International Research Publication House. https://dx.doi.org/10.37624/IJERT/13.10.2020.2778-2787

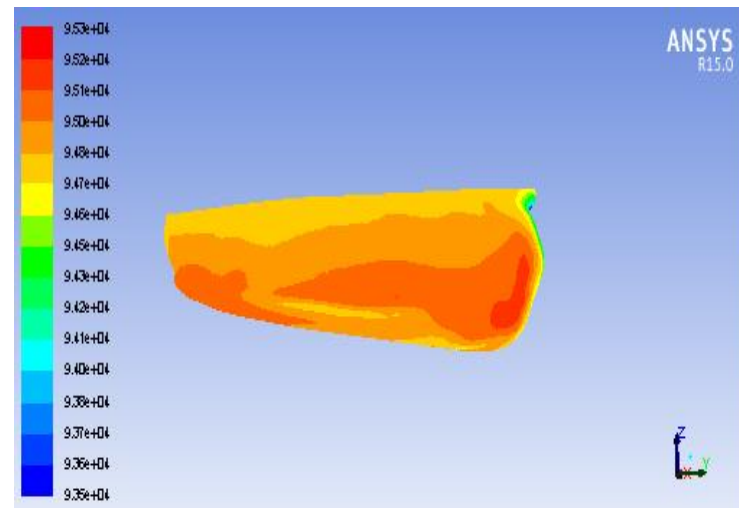

c)

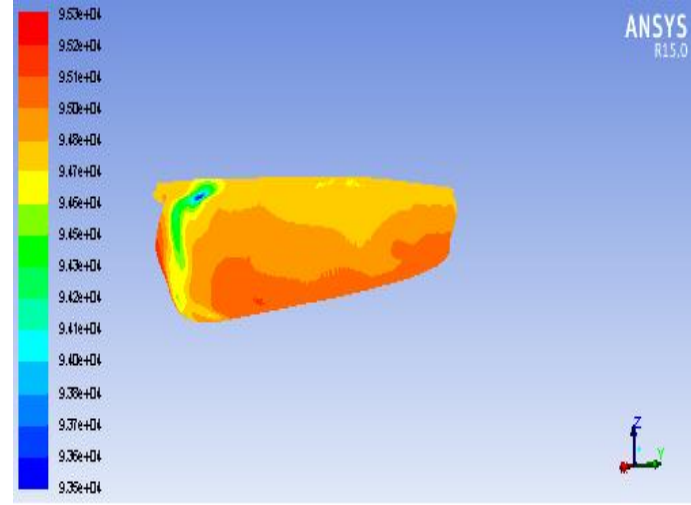

d)

Figure 9. Simulation results of pressure distribution on starboard-side and port-side of the ship's hull which under the waterline with the 3D problem: (a, b) $\theta=010^{\circ}$ and $V_{m}=0.45 \mathrm{~m} / \mathrm{s} ;$ (c, d) $\theta=030^{\circ}$ and $V_{m}=0.75 \mathrm{~m} / \mathrm{s}$

\section{III.II. The result of the additional force}

Due to the pressure distribution and the pressure coefficients are asymmetric on two-side of the ship, and base on the simulation results mentioned above, it is completely determined the additional force, including additional resistance force, additional centrifugal force and additional torque were described in Table 1.

Table 1: Summary of simulation calculation results of each case when the ship changes the course

\begin{tabular}{|c|c|c|c|c|c|}
\hline \multicolumn{2}{|c|}{$\begin{array}{c}\text { The speed of ship } \\
\text { model }(\mathbf{m} / \mathbf{s})\end{array}$} & $\mathbf{0 . 4 5}$ & $\mathbf{0 . 5 5}$ & $\mathbf{0 . 6 5}$ & $\mathbf{0 . 7 5}$ \\
\hline \multirow{2}{*}{$\begin{array}{c}\text { The } \\
\text { additional } \\
\text { resistance } \\
\text { force }(\mathrm{N})\end{array}$} & Steady & 0.314 & 0.376 & 0.523 & 0.698 \\
\cline { 2 - 6 } & $\theta=010^{0}$ & 0.354 & 0.471 & 0.612 & 0.715 \\
\cline { 2 - 6 } & $\theta=030^{0}$ & 0.855 & 1.009 & 1.317 & 2.027 \\
\hline \multirow{4}{*}{$\begin{array}{c}\text { The } \\
\text { additional } \\
\text { centrifugal } \\
\text { force }(\mathrm{N})\end{array}$} & $\theta=010^{0}$ & 0.047 & 0.065 & 0.083 & 0.148 \\
\cline { 2 - 6 } & $\theta=020^{0}$ & 0.0065 & 0.0121 & 0.0180 & 0.0240 \\
\cline { 2 - 6 } & $\theta=030^{0}$ & 0.0015 & 0.0085 & 0.0120 & 0.0180 \\
\hline \multirow{2}{*}{$\begin{array}{c}\text { The } \\
\text { additional } \\
\text { torque } \\
(\mathrm{N} . \mathrm{m})\end{array}$} & $\theta=010^{0}$ & 0.09 & 1.0 & 3.521 & 4.824 \\
\cline { 2 - 6 } & $\theta=020^{0}$ & 0.15 & 1.9 & 11.59 & 21.62 \\
\cline { 2 - 6 } & $\theta=030^{0}$ & 0.27 & 7.02 & 22.14 & 32.15 \\
\hline
\end{tabular}

From the results in Table 1, build on the same graph depicting the range of additional resistance force, additional centrifugal force, and the additional torque according to velocity, when the ship alters the course, which was shown in Fig 10 to Fig 12.
A. For the value of additional resistance force acting on the vessel when altering its course

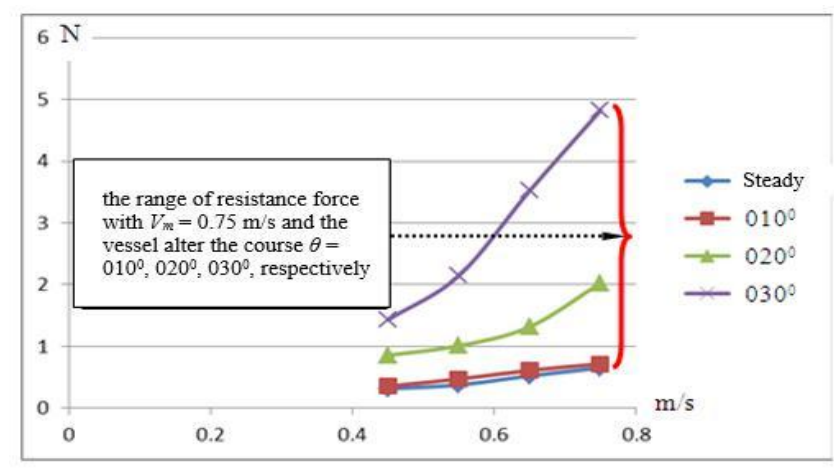

a)

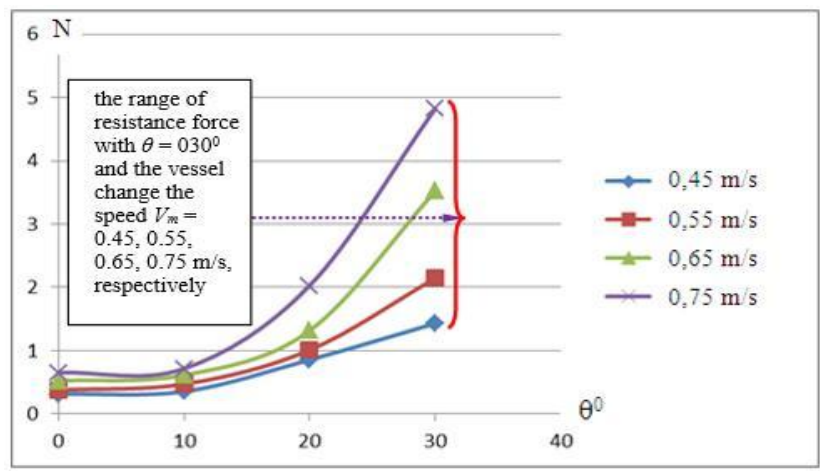

b)

Figure 10: The graph depicting the range of additional resistance force, when the vessel is steady alter its courses: a) $V_{m}=0.75 \mathrm{~m} / \mathrm{s}$ and $\theta=\left\{010^{\circ} ; 020^{\circ} ; 030^{\circ}\right\}$; b) $\theta=030^{\circ}$ and $V_{m}=\{0.45 ; 0.55 ; 0.65$; $0.75\}$

The results from Table 1 and Fig 10 showed that:

- The additional resistance force of the model ship increases rapidly, when the value of the direction of motion changes, with the same value of $V_{m}$. 
International Journal of Engineering Research and Technology. ISSN 0974-3154, Volume 13, Number 10 (2020), pp. 2778-2787

(C) International Research Publication House. https://dx.doi.org/10.37624/IJERT/13.10.2020.2778-2787

When $V_{m}=0.45 \mathrm{~m} / \mathrm{s}$, the additional resistance force of the model ship increases:

$R_{m}=1,430 \mathrm{~N}-0.314 \mathrm{~N}=1,116 \mathrm{~N}$

When $V_{m}=0.75 \mathrm{~m} / \mathrm{s}$, the additional resistance force of the model ship increases:

$R_{m}=4,824 \mathrm{~N}-0.698 \mathrm{~N}=4,126 \mathrm{~N}$

- The additional resistance force of the ship model increases rapidly, with the same value of the direction of motion when the speed of the model ship $V_{m}=0.45,0.55,0.65$ and 0.75 $\mathrm{m} / \mathrm{s}$, respectively.

When the ship is steady, the additional resistance force of the ship model increases: $R_{m}=0.698 \mathrm{~N}-0.314 \mathrm{~N}=0.384 \mathrm{~N}$

When changing the course $\theta=010^{\circ}$, the additional resistance force of the ship model increased $R_{m}=0.715 \mathrm{~N}-0.354 \mathrm{~N}=$ $0.361 \mathrm{~N}$

When changing the course $\theta=030^{\circ}$, the additional resistance force of the ship model increased $R_{m}=4.824 \mathrm{~N}-1.430 \mathrm{~N}=$ $3.394 \mathrm{~N}$

In case of the additional resistance force of real vessel $\left(R_{S}\right)$ : when changing the maximum course $\theta=030^{\circ}$ (Fig 10b) is converted as: $R_{s}=3.394 \times k^{3}=3.394 \times 10^{6} \mathrm{~N}$

In the case when the speed of ship velocity $V_{m}=0.75 \mathrm{~m} / \mathrm{s}$, and the course was largest changed $\theta=030^{\circ}$, then additional resistance force of the ship model is very fast, specifically:

$R_{m}=4.824 \mathrm{~N}-0.698 \mathrm{~N}=4.126 \mathrm{~N}$

At that time, the additional resistance force on the real ship is converted by:

$R_{s}=4.126 \times k^{3}=4.126 \times 10^{6} \mathrm{~N}$

Thus, the value of additional resistance force increased rapidly leading to a rapid reduction of the vessel's speed, because the propeller thrust could not overcome the additional resistance force, so the process of ship's maneuvering needed to change the course appropriately.

- The graph of additional resistance force corresponding to different velocity when changing the course of the ship (Fig $10)$, has a $3^{\text {rd }}$-degree curve partial and satisfies the general equation of the form:

$$
R=a \theta^{3}+b \theta^{2}+c \theta+d
$$

Determine the variables $a, b, c$, when the velocity changes, completely calculate the value of additional resistance force $R m$ :

$V_{m}=0.75 \mathrm{~m} / \mathrm{s}$ :

$R=0,00003167 \theta^{3}+0,005525 \theta^{2}-0,05672 \theta+0,698$

$V_{m}=0.65 \mathrm{~m} / \mathrm{s}:$

$R=0,0001472 \theta^{3}+0,001335 \theta^{2}-0,007533 \theta+0,523$

$V_{m}=0.55 \mathrm{~m} / \mathrm{s}$ :

$R=0,00002567 \theta^{3}+0,001445 \theta^{2}-0,007517 \theta+0,376$
$V_{m}=0.45 \mathrm{~m} / \mathrm{s}:$

$R=-0,0000645 \theta^{3}+0,000424 \theta^{2}-0,03195 \theta+0,314$

B. For the value of additional centrifugal force acting on the ship when the direction of motion is changed:

Analyze the results according to Table 1 and Fig 11, remarking that:

- The additional centrifugal force of the ship model will increase when the value of $\theta=\left\{010^{0} ; 020^{\circ} ; 030^{\circ}\right\}$, with the same $V_{m}$ value, specifically:

When $V_{m}=0.45 \mathrm{~m} / \mathrm{s}$, the centrifugal force of the model ship increases:

$F_{l t}=0.047 \mathrm{~N}-0.0015 \mathrm{~N}=0.0455 \mathrm{~N}$

When $V_{m}=0.55 \mathrm{~m} / \mathrm{s}$, the centrifugal force of the model ship increases:

$F_{l t}=0.065 \mathrm{~N}-0.0085 \mathrm{~N}=0.0565 \mathrm{~N}$

When $V_{m}=0.65 \mathrm{~m} / \mathrm{s}$, the centrifugal force of the model ship increases:

$F_{l t}=0.083 \mathrm{~N}-0.0120 \mathrm{~N}=0.0710 \mathrm{~N}$

When $V_{m}=0.75 \mathrm{~m} / \mathrm{s}$, the centrifugal force of the model ship increases:

$F_{l t}=0.148 \mathrm{~N}-0.0180 \mathrm{~N}=0.1300 \mathrm{~N}$

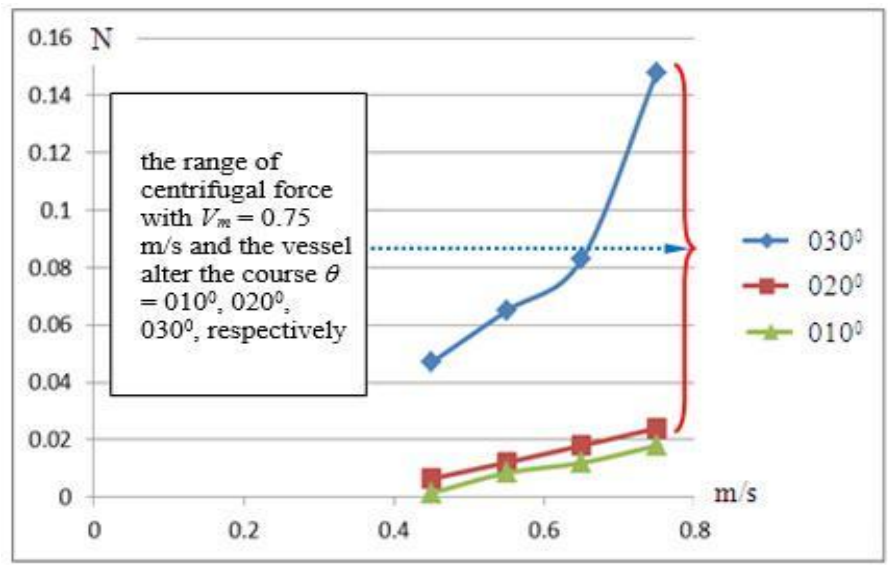

Figure 11: Graph depicting the range of the additional centrifugal force value when the ship changed direction $\theta=\left\{010^{\circ} ; 020^{\circ} ; 030^{\circ}\right\}$ and the corresponding velocity increase $V_{m}=\{0.45 ; 0.55 ; 0.65 ; 0.75\}$

- The additional centrifugal force of the ship model increases rapidly, when the value of the model speed $V_{m}=\{0.45 ; 0.55$; $0.65 ; 0.75\}(\mathrm{m} / \mathrm{s})$, with the same value of the direction of motion of the ship:

When $\theta=010^{\circ}$, the centrifugal force of the model ship increases:

$F_{l t}=0.148 \mathrm{~N}-0.047 \mathrm{~N}=0.101 \mathrm{~N}$

When $\theta=020^{\circ}$, the centrifugal force of the model ship increases:

$F_{l t}=0.0240 \mathrm{~N}-0.0065 \mathrm{~N}=0.0175 \mathrm{~N}$ 
International Journal of Engineering Research and Technology. ISSN 0974-3154, Volume 13, Number 10 (2020), pp. 2778-2787

(C) International Research Publication House. https://dx.doi.org/10.37624/IJERT/13.10.2020.2778-2787

When $\theta=030^{\circ}$, the centrifugal force of the model ship increases:

$F_{l t}=0.0180 \mathrm{~N}-0.0015 \mathrm{~N}=0.0165 \mathrm{~N}$

- The actual centrifugal force on the vessel when changing the maximum direction of motion $\theta=030^{\circ}$ and $V_{m}=0.75 \mathrm{~m} / \mathrm{s}$, which calculated by:

$F_{l t}=0.0180 \times k^{3}=0.0180 \times 10^{6} \mathrm{~N}$

\section{For the additional torque acting to the vessel}

The Fig 12 depicted the additional centrifugal force values at different velocities, with changes in the direction of motion of the vessel.

- The additional torque of the ship model with the same value $V_{m}$ will increase, when the value of the direction of ship's course: $\theta=\left\{010^{\circ} ; 020^{\circ} ; 030^{\circ}\right\}$, respectively:

When $V_{m}=0.45 \mathrm{~m} / \mathrm{s}$, the additional torque of the ship model:

$M_{g l}=0.27$ N.m -0.08 N.m $=0.19$ N.m

When $V_{m}=0.55 \mathrm{~m} / \mathrm{s}$, the additional torque of the ship model:

$M_{g l}=7.02 \mathrm{~N} \cdot \mathrm{m}-1.00 \mathrm{~N} \cdot \mathrm{m}=6.02 \mathrm{~N} \cdot \mathrm{m}$

When $V_{m}=0.65 \mathrm{~m} / \mathrm{s}$, the additional torque of the ship model:

$M_{g l}=22.14$ N.m -7.88 N.m $=14.26$ N.m

When $V_{m}=0.75 \mathrm{~m} / \mathrm{s}$, the additional torque of the ship model:

$M_{g l}=32.15$ N.m -10.89 N.m $=21.26$ N.m

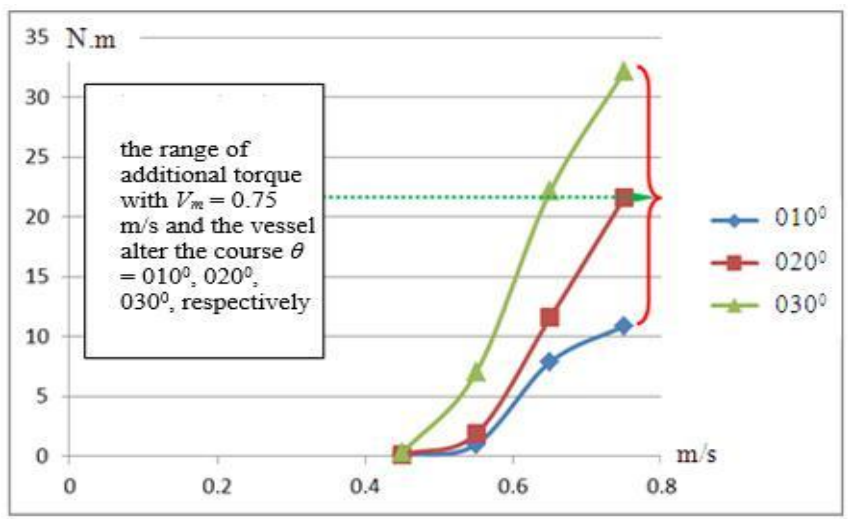

Figure 12. The graph depicts the range of additional torque values with velocity when the ship changed direction $\theta=010^{\circ} ; 020^{\circ} ; 030^{\circ}$, respectively

- The additional torque of the ship model increases rapidly, when the value of the model speed $V_{m}=\{0.45 ; 0.55 ; 0.65$; $0.75 \mathrm{r} / \mathrm{s}$, with the same value of the direction of motion of the ship:

When $\theta=010^{\circ}$, the additional torque: $M_{g l}=10.89$ N.m -0.09 $\mathrm{N} . \mathrm{m}=10.78$ N.m

When $\theta=020^{\circ}$, the additional torque: $M_{g l}=21.62 \mathrm{~N} . \mathrm{m}-0.15$ N.m $=21.47$ N.m

When $\theta=030^{\circ}$, the additional torque: $M_{g l}=32.15$ N.m -0.27 $\mathrm{N} . \mathrm{m}=31.88 \mathrm{~N} . \mathrm{m}$
- The actual additional torque on the real vessel when changing the maximum direction of motion $\theta=030^{\circ}$ and $V_{m}=0.75 \mathrm{~m} / \mathrm{s}$, which calculated by:

$M_{g l}=32.15 \times k^{4}=32.15 \times 10^{8}$ N.m

\section{EXPERIMENTAL VERIFICATION}

Conducting experimental research to verify a part of the simulation results is the additional resistance force value on the ship at the Ship Model Test Tank of Vietnam Maritime University. There are some key parameters:

- Length: $50 \mathrm{~m}$;

- Width: $2.0 \mathrm{~m}$;

- Depth: $1.5 \mathrm{~m}$;

- Tank wall thickness: $0.5 \mathrm{~m}$;

- Maximum speed: $3.2 \mathrm{~m} / \mathrm{s}$;

- The deviation of the test tank system: $1.5 \%$

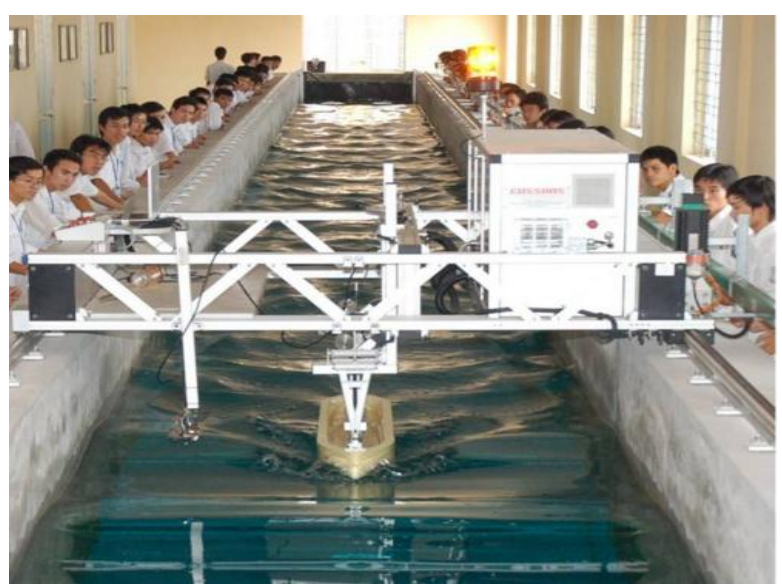

(a)

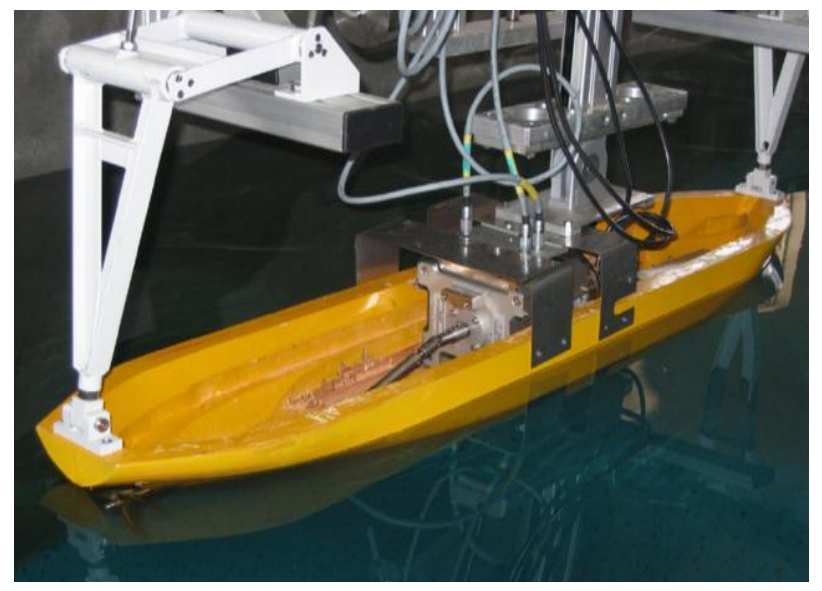

(b)

Figure 13: The Ship Model Test Tank at Vietnam Maritime University (a) and the research model vessel attached to the trailer (b) 
International Journal of Engineering Research and Technology. ISSN 0974-3154, Volume 13, Number 10 (2020), pp. 2778-2787

(C) International Research Publication House. https://dx.doi.org/10.37624/IJERT/13.10.2020.2778-2787

Table 2 and Table 3 summarized the results of the additional resistance force value measurements on the ship model identical to the real ship M/V TAN CANG FOUNDATION and the conversion value on the real ship, respectively when changing the direction of motion.

Table 2: Summary of additional resistance force value measurements on the ship model

\begin{tabular}{|c|c|c|c|c|}
\hline \multirow{2}{*}{$V_{m}(\mathrm{~m} / \mathrm{s})$} & \multicolumn{4}{|c|}{ Change the direction of motion of the ship model } \\
\cline { 2 - 5 } & $000^{0}$ & $010^{0}$ & $020^{0}$ & $030^{0}$ \\
\cline { 2 - 5 } & \multicolumn{4}{|c|}{ Additional resistance force value $R_{m}(\mathrm{~N})$} \\
\hline 0.45 & - & 0.363 & 0.875 & 1.63 \\
\hline 0.55 & 0.463 & 0.457 & 1.089 & 2.544 \\
\hline 0.65 & 0.552 & 0.570 & 1.517 & 3.821 \\
\hline 0.75 & 0.842 & 0.752 & 2.187 & 5.224 \\
\hline
\end{tabular}

Table 3: Summary of corresponding additional resistance force value in the real ship when changing direction

\begin{tabular}{|c|c|c|c|c|c|}
\hline \multirow{2}{*}{$\begin{array}{c}* \\
\text { V }\end{array}$ (knots) } & \multirow{2}{*}{$V_{S}(\mathrm{~m} / \mathrm{s})$} & \multicolumn{5}{|c|}{$\begin{array}{c}\text { Change the direction of motion of the } \\
\text { real ship }\end{array}$} \\
\cline { 3 - 6 } & & $000^{0}$ & $010^{0}$ & $020^{0}$ & $030^{0}$ \\
\cline { 3 - 6 } & & Additional resistance force value $R_{S}(\mathrm{kN})$ \\
\hline 8.75 & 4.5 & - & 363.0 & 875.0 & 1630.0 \\
\hline 10.70 & 5.5 & 287.7 & 457.0 & 1089.0 & 2544.0 \\
\hline 12.65 & 6.5 & 315.0 & 570.0 & 1517.0 & 3821.0 \\
\hline 14.59 & 7.5 & 546.9 & 752.0 & 2187.0 & 5224.0 \\
\hline
\end{tabular}

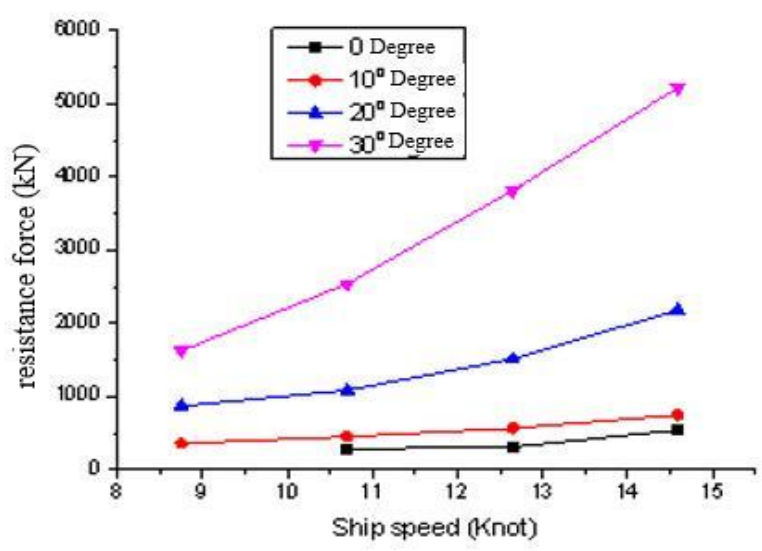

a)

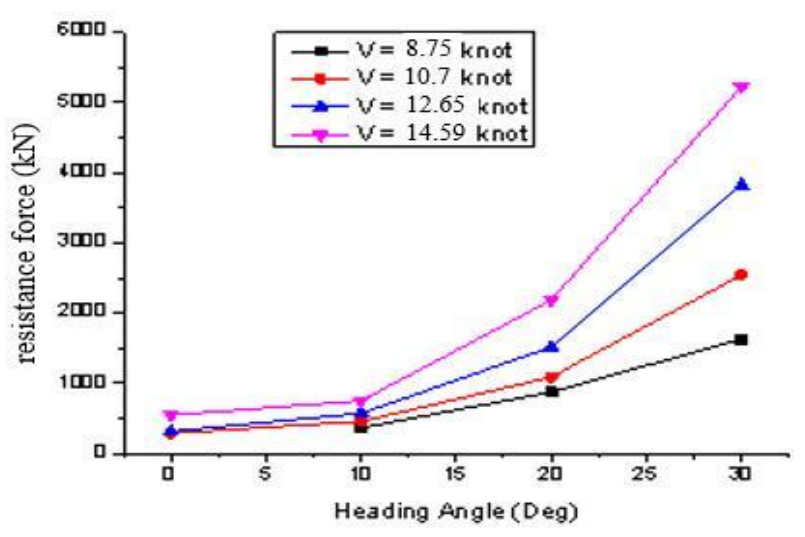

b)

Figure 14: Graph of the relationship between additional resistance force value with ship speed velocity when changing the direction of motion (a); with the direction of motion when changing the ship's speed (b)

Table 4 gave a summary, comparing the results of simulation calculations by CFD with Fluent - Ansys, and experiment. At the same time, construct a graph of the relationship between the measured additional resistance force value and the speed of the model ship, the movement direction of the model ship according to Figure 14.

Table 4. Summary of CFD simulation results with Fluent - Ansys, and experiment

\begin{tabular}{|c|c|c|c|c|c|c|c|c|}
\hline \multirow{3}{*}{$V_{m}(\mathrm{~m} / \mathrm{s})$} & \multicolumn{7}{|c|}{ Change the direction of motion of the ship } \\
\cline { 2 - 9 } & \multicolumn{2}{|c|}{$000^{0}$} & \multicolumn{2}{|c|}{$010^{0}$} & \multicolumn{2}{c|}{$020^{0}$} & \multicolumn{2}{c|}{$030^{0}$} \\
\cline { 2 - 9 } & Experiment & CFD & Experiment & CFD & Experiment & CFD & Experiment & CFD \\
\hline 0.45 & - & 0.314 & 0.363 & 0.354 & 0.875 & 0.855 & 1.63 & 1.43 \\
\hline 0.55 & 0.463 & 0.376 & 0.457 & 0.471 & 1.089 & 1.009 & 2.544 & 2.144 \\
\hline 0.65 & 0.552 & 0.523 & 0.570 & 0.612 & 1.517 & 1.317 & 3.821 & 3.521 \\
\hline 0.75 & 0.842 & 0.698 & 0.752 & 0.715 & 2.187 & 2.027 & 5.224 & 4.824 \\
\hline
\end{tabular}




\section{CONCLUSION}

The article has built a research model, a mathematical model, and performed the calculating simulation of the impact of additional forces on the vessel when altering the course by CFD with Fluent - Ansys, including: additional resistance forces, additional centrifugal force, and additional torque. Therefrom, specific simulation calculations are applied based on data similar to those of M/V TAN CANG FOUNDATION. The results indicated that: When the direction of the vessel is changed with the speed changing dramatically, the additional torque generated will increase rapidly, causing the risk of instability of the ship, even leading to the capsizing of the ship.

The article compared the simulation results calculated by CFD with Fluent - Ansys and the experimental research results of the additional resistance value impacting on ships. With the same input requirements of the problem but the calculated results by CFDs with Fluent - Ansys and experimental studies have an average deviation for 15 calculation cases of $8.4 \%$ (except for ships steady at a small speed of $0.45 \mathrm{~m} / \mathrm{s}$ ). If comparing the results of CFD simulation with Fluent - Ansys and empirical studies on ship models (similar to the model ships in the article) was published by Brendan Smoker, the biggest average deviation of $6.04 \%$ [16]. The simulation results of this research ensure accuracy, reliability, and have acceptable deviation.

\section{ACKNOWLEDGEMENTS}

The authors would like to thank all colleagues in Vietnam Maritime University for assistance during the work. Additionally, we appreciate the constructive suggestions of the anonymous reviewers, which are invaluable in improving the quality of the manuscript.

\section{REFERENCES}

[1] H.X. Liu, X. Kui, and Y.B. Zhao, Numerical investigation on the penetration of gravity installed anchors by a coupled Eulerian-Lagrangian approach, Applied Ocean Research, 60, 2016, 94-108.

[2] D.Y. Kemal, O. Turan, and A. Incecik, Predicting the effect of biofouling on ship resistance using CFD, Applied Ocean Research, 62, 2017, 100-118.

[3] G. Floris, J. Montewka, W.B. Zhang, and P. Kujala, An analysis of ship escort and convoy operations in ice conditions, Safety Science, 95, 2017, 198-209.

[4] Z.J. Min, C.W. Hao, H.W. Qing, G.Y. Jun, and L. T. Zeng, Numerical study on the six-DOF anchoring process of gravity anchor using a new mesh update strategy, Marine Structures, 52, 2017, 173-187.

[5] K. Niklas, and H. Pruszko, Full-scale CFD simulations for the determination of ship resistance as a rational, alternative method to towing tank experiments, Ocean Engineering, 15, 2019, 106435.
[6] D.M. Park, J.H. Kim, and Y.W. Kim, Numerical study of added resistance of flexible ship, Journal of Fluids and Structures, 85, 2019, 199-219.

[7] K. Song, C. Guo, C. Wang, C. Sun, P. Li, and W. Wang, Numerical analysis of the effects of stern flaps on ship resistance and propulsion performance, Ocean Engineering, 193, 2019, 106621.

[8] S. Kaidia, E. Lefrançois, and H. Smaoui, Numerical modelling of the muddy layer effect on Ship's resistance and squat, Ocean Engineering, 199, 2020, 106939.

[9] H.K. Versteeg, and W. Malalasekera, An introduction to computational fluid dynamics The finite volume method (Second Edition) (Pearson, 2007).

[10] R. Peyret, Handbook of Computational Fluid Mechanics, (Academic Press, 1996).

[11] ANSYS Fluent Theory Guide (U.S.A, 2013).

[12] M.W. Frank, Fluid Mechanics (5 $5^{\text {th }}$ Edition), McGrawHill Series in Mechanical Engineering, (McGraw-Hill, 2002).

[13] K.J. Rawson, and E.C. Tupper, Basic ship theory (5 $5^{\text {th }}$ Edition), (Butterworth-Heinemann, 2001), https://doi.org/10.1016/B978-0-7506-5398-5.X5000-6.

[14] J.J.D. Anderson, Fundamental of aerodynamics $\left(5^{\text {th }}\right.$ Edition), (McGraw-Hill Education, 2010), https://doi.org/10.1016/C2009-0-63410-3.

[15] J.P. Breslin, and P. Andersen, Hydrodynamics of Ship Propellers, (Cambridge University Press, 2010), https://doi.org/10.1017/CBO9780511624254.

[16] B. Smoker, Escort Tug Performance Prediction: A CFD Method, Master dissertation, Department of Mechanical Engineering, University of Victoria, 2012. 